Revista aSEPHallus de Orientação Lacaniana

Núcleo Sephora de Pesquisa sobre o Moderno e o Contemporâneo

ISSN 1809 - 709 X

\title{
Um estudo sobre o real e sua relação com a invenção artística e psicanalítica
}

\author{
Letícia Mello \\ Psicóloga, psicanalista \\ Mestre em psicanálise pela Universidade Paris VIII Vincennes Saint-Denis (Paris, França) \\ Doutoranda pela Universidade Paris VIII Vincennes Saint-Denis (Paris, França) \\ E-mail: leticiacsm@hotmail.com
}

\begin{abstract}
Resumo
Este artigo aborda o tema da invenção a partir da noção do savoir-y-faire com o real proposta por Lacan ao final de seu ensino e faz um paralelo entre a invenção artística e a invenção analítica. Inventar algo com o real enquanto letra implica na criação de um artifício para lidar com a impossibilidade de tudo dizer e tudo representar. Entretanto, as operações artísticas não fazem do sujeito um artista do mesmo modo como a conclusão de uma análise não forma um analista. $\mathrm{A}$ diferença entre os mecanismos de criação artístico e analítico será discutida no presente texto.

Palavras-chave: real, letra, sinthoma, arte contemporânea, invenção.
\end{abstract}

\section{Une étude sur le réel et sa relation avec l'invention artistique et psychanalytique}

Ce travail adresse la question de l'invention a partir de la notion de savoir-y-faire avec le réel proposée par Lacan a la fin de ses cours et établit un parallèle entre l'invention artistique et l'invention analytique. Inventer quelque chose avec le réel en tant que lettre implique la création d'un artifice pour faire face à l'impossibilité de tout dire et de tout représenter. Cependant, les opérations artistiques ne font pas du sujet un artiste autant que la conclusion d'une analyse ne forme pas un analyste. La différence entre les méchanismes de création artistique et analytique sera discutée au cours du texte.

Mots-clés: réel, lettre, sinthome, art contemporain, invention.

\section{A study on the real and its relationship with the invention and artistic psychoanalytic}

This article deals with the issue of invention based on the concept of savoir-y-faire with the real invented by Lacan in the end of his teachings and finds similarities between artistic invention and analytic invention. Inventing something with the real as far as letter involves the creation of a scheme to deal with the impossibility to say and to represent everything. However, artistic operations do not make an artist, in the same way that the end of an analysis doesn't produce an analyst. The difference between the mechanisms of artistic and analytical creation will be discussed in this text.

Keywords: real, letter, sinthoma, contemporary art, invention. 


\title{
Um estudo sobre o real e sua relação com a invenção artística e psicanalítica ${ }^{1}$
}

\author{
Letícia Mello
}

\section{Introdução}

No presente artigo, defenderemos a ideia segundo a qual o discurso produzido na arte contemporânea mantém aspectos análogos ao sinthoma abordado no último momento do ensino de Lacan, na medida em que tanto a arte quanto a psicanálise rompem com o semblante e recorrem à invenção de um artifício como forma de lidar com o real. Tanto o artista quanto o analista fazem uma operação de redução do imaginário deixando em suas invenções a marca assemântica que institui o real. É nesse sentido que a arte contemporânea e a psicanálise lacaniana ganham um lugar comum.

\section{I - Quando o real é contornado pela arte}

No seminário sobre a ética da psicanálise, Lacan (1959-1960) compreende a sublimação como uma tentativa de reorganizar alguma coisa em torno do vazio deixado pelo objeto perdido. Este vazio é reconhecido por Lacan como das Ding, a Coisa abordada por Freud no seu "Projeto para uma psicologia científica" (1895). A Coisa é o que resiste a qualquer tentativa de significação ou de representação, ela é o lugar vazio. Ela é, em sua essência, irredutível a uma imagem ou a um significante e evoca a falta, na medida em que é definida como o elemento "em torno do qual se orienta todo caminho do sujeito" (Lacan, 1959-1960, p. 69). A Coisa é, por assim dizer, a própria inexistência do objeto. É essa falta que mantém vivo o desejo e é com ela que o sujeito deverá lidar ao longo de sua existência.

A partir daí, nesse seminário, Lacan argumenta que a sublimação é uma forma de "organização do vazio". O termo sublimação é quase sempre associado à criação artística, assim Lacan opõe em seu texto, o discurso da arte ao discurso dogmático da religião e ao discurso especializado da ciência. 0 psicanalista sustenta a ideia de que na criação artística o sujeito não evita o vazio da Coisa. Enquanto a ciência ou a religião preenchem esse vazio com o autoritarismo de seus discursos, a arte captura o objeto na medida em que não nega das Ding (Lacan, 19591960, p. 155). Isso quer dizer que é na arte que o objeto que falta - objeto $a$ - pode existir. A arte coloca o vazio no centro da criação e é com ele que o artista trabalha. Em última instância, a obra de arte constrói uma borda significante em torno desse lugar vazio que é também definido como real. Por isso pode-se concluir que a arte é uma forma de circunscrição da Coisa. Ela é, antes de tudo, um indício do real ou, segundo Lacan, um objeto criado em torno do vazio. Isso quer dizer que o artista não apaga a Coisa, ele a conserva no centro de sua criação.

Esta via assumida pela arte permite a Lacan (1959-1960, p. 139) caracterizar a sublimação ex-nihilo como uma forma de criação que se associa ao nada. Mas, ao invés de estabelecer uma 
relação com a posição divina na qual a criação acontece a partir do nada, o psicanalista acentua que o nada do qual se trata permanece no centro da criação. Considerando que é a partir do vazio que o artista cria sua obra, Lacan retoma a metáfora do vaso para esclarecer como isso se constrói. Na medida em que o oleiro molda o vaso, ele contorna um espaço vazio e o nada aí "figurado" vai ganhando um lugar central. O vaso torna-se para Lacan o objeto modelo. Essa coisa vazia que se produz no centro do objeto recupera a dimensão real da criação. Assim, é na arte que um objeto comum e corriqueiro como o vaso pode ser "elevado à dignidade da Coisa" (Lacan, 1959-1960, p. 133), isto é, quando o nada se representa na obra.

A arte do século XX é aquela que revela esse lado indizível do objeto na medida em que quebra as evidências preestabelecidas a ele concernidas. Subvertendo a tradição, os artistas contemporâneos a Duchamp abandonam a mimese, a representação e a técnica e criam suas obras com objetos corriqueiros, industrializados, desvalorizados ou dejetos. Transformados em obra, tais objetos perdem seu aspecto dado e tem sua dignidade renovada (Recalcati, 2009, p. 99). A novidade da arte moderna consiste, portanto, nessa renovação do uso do objeto. A arte abandona o ideal do objeto inédito e produzido com perfeição técnica e faz uma bricolagem significante, dando aos objetos já existentes uma nova significação. O artista encontra um objeto e renova seu utilitarismo, ou seja, transforma-o em algo que está para além da lógica do útil para a qual fora destinado. $O$ exemplo dado por Lacan são as caixas de fósforos de Jacques Prévet que foram dispostas de uma maneira agradável, se enfileirando uma depois da outra para decorar sua casa. Uma caixa de fósforos assim utilizada não é simplesmente um objeto cujo uso é previsível (Lacan, 1959-1960, p. 136). O uso fora do padrão fez a Coisa subsistir nessas caixas de fósforos na medida em que convoca a seguinte pergunta: afinal, o que é isso, seriam caixas contendo palitos de trissulfureto fosfórico que quando em atrito com objetos de superfícies ásperas se decompõem, ardem e incendeiam produzindo fogo, ou se trata de uma escultura? Longe da representação metafórica da arte tradicional, causar um enigma no espectador e assim fazer vacilar sua passiva e confortável posição contemplativa, convocar o espectador em sua posição de sujeito, eis aí a marca radical que determina a arte dos tempos modernos.

\section{II - Quando a arte promove o encontro com o real}

Como vimos, em 0 seminário, livro 7, Lacan aborda o real em sua relação com das Ding. A sublimação seria uma forma de colocar uma tela diante de o inapreensível do real a partir do pressuposto de que só é possível se aproximar da Coisa através de um véu, isto é, fazendo uma borda. Se, nesse seminário sobre a ética, a arte aparece como uma forma de organização e de bordeamento do irrepresentável da Coisa, naquele de 1964-1965, sobre os conceitos fundamentais, ela perde essa vertente de circunscrição do vazio. A arte passa a ser compreendida como aquilo que permite o encontro com o real (Recalcati, 2009, p. 101). No seminário de 19591960, a sublimação tinha a função de contornar o real. Naquele de 1964-1965, o real não é escondido ou velado numa obra de arte, ele se apresenta nela como a confirmação da falta. 
No Seminário 11, na parte em que Lacan aborda a função do olhar, ele se pergunta o que seria um quadro (1964-1965, p. 66). Aquilo que ele denomina "função quadro" especifica a condição fundamental da obra de arte. Contrariamente à pressuposição de que é o espectador que contempla a obra, Lacan lança a ideia de que é a obra que captura o sujeito. O sujeito capturado é entregue ao olhar do Outro. Nessa perspectiva, o olhar é localizado fora do sujeito. Seu olho é tomado pelo quadro e, nessa medida, ele se torna objeto do olhar do Outro. Ele é olhado pelo quadro e assim é retirado de sua confortável posição de mestre da visão para se submeter a um olhar suposto fora da cena. O sujeito era aquele que olhava, agora ele é surpreendido sendo olhado "Eu sou olhado, quer dizer que eu sou o quadro" (Lacan, 1964-1965, p. 103).

Quando a barreira simbólica do belo deixa de existir no contexto da arte, surge em seu lugar aquilo que Lacan define como "figura anamórfica". Uma mancha presentifica o não figurável, o real, portanto. Nesse caminho, a "função quadro" é posta por Lacan em referência ao real da castração. O olhar comanda, mas ao mesmo tempo escapa à visão (Lacan, 1964-1965, p. 78). O sujeito é entregue ao olhar do Outro e se encontra, desta forma, sendo olhado em sua essência, em sua falta. Na medida em que a obra traz à tona a mancha, ela fura a organização semântica do quadro e revela o sujeito como mancha, como castrado. Ele se encontra aniquilado e sem representação.

Lacan toma o quadro de Holbein intitulado "Os embaixadores" como paradigma, no qual parte daquilo que está no campo da visão é reduzido à anamorfose, ou seja, a uma deformação superficial. A mancha transversal posta no centro da cena que, num primeiro olhar parece um objeto fálico é, na verdade, a encarnação terrificante da castração humana (Lacan, 1964-1965, p. 88). O espectador precisa se afastar e se dirigir um pouco para a esquerda para que o quadro mostre que se trata de outra coisa. O sujeito é tomado pelo quadro e surpreendido pelo terror quando enxerga nele uma caveira. Nesta mancha anamórfica o espectador cai na armadilha do olhar e descobre, nesse instante, a dura realidade da castração. A falta é mostrada ao sujeito que, por sua vez, recupera sua posição subjetiva enquanto ser castrado. Olhar é se deixar ser visto e, deixar-se ver é se deixar castrar (Rivera, 2005). Assim, Lacan desvela através do jogo do trompel'œeil do quadro a problemática do real em torno do horror da castração na medida em que denuncia o equívoco do inconsciente no campo visual. Desta forma, compreendemos que na arte quando o belo é deposto e o visual desvalorizado, o sujeito é levado a lidar com sua falta estrutural. É o real revelando aquilo que aterroriza o sujeito.

No século $X X$, essa relação com o real é levada ao extremo, posto que não existe mais simbolismo no campo da arte. Não há mais um significado latente, metaforizado ou a espera de ser interpretado na obra. Tampouco existe um realismo. No lugar de contemplar a obra, o espectador é convidado a pensar sobre ela. A tomada de posição à qual o sujeito é convocado na arte moderna recoloca-o em cena como sujeito barrado, sujeito do qual a psicanálise se ocupa. É nessa passagem de espectador passivo, da arte tradicional, a sujeito implicado na obra trazido à cena pela modernidade, que a arte reabre um diálogo com a psicanálise. 
A arte rompe com a ilusão da imagem e com a interpretação de sentido. Os artistas realizam suas obras com objetos industrializados ou desprezados, com a finalidade de trazê-los de volta ao olhar da sociedade. Com este ato ele traz a falta à cena desvelando a castração. Desta forma, a obra de arte revela a falta estrutural e constitutiva do ser humano.

\section{III - Quando o real se figura na arte}

A mudança teórica relativa à sublimação entre os Seminários 7 e 11 se estrutura essencialmente sobre a noção de como o artista lida com o real através da construção de um objeto de arte. Enquanto ao final dos anos 1950 Lacan falava do real a partir de das Ding, como um absoluto inatingível e somente contornável pela obra, em meados dos anos 1960 o real se configura como aquilo que coloca o sujeito diante da castração pela figura anamórfica inserida na obra (Recalcati, 2005, p. 99). No início dos anos 1970, Lacan mostra o modo como o real está relacionado com a verdadeira subjetividade do sujeito. A tese lacaniana do real como letra nos permitirá desenvolver no presente texto um diálogo com a arte contemporânea.

Especificamente no texto "Lituraterra", de 1971, o real ganha um estatuto subversivo e radical na obra de Lacan. Ele se liga àquilo que o psicanalista definiu como letra, isso quer dizer que ele está articulado à total falta de significação, ao furo da linguagem, à insuficiência do simbólico. Com efeito, neste texto, Lacan aproxima a definição de letra ao limite entre o saber e o gozo. Em outras palavras, a letra marca radicalmente a diferença entre o saber enquanto elucubração da verdade e o gozo enquanto um ponto inapreensível desta verdade. A letra é a literalidade da língua subjetiva que determina o sujeito. Ela é o significante que sulca o sujeito com um traço singular, irredutível à universalidade do significante. Trata-se de signos que se desenham de maneira única em cada sujeito. A letra é, assim, a consequência do acontecimento significante que dá literalidade ao sujeito. Ela não produz uma significação, sua relação com a cadeia de significantes é singular para cada sujeito. O significante serve de instrumento que evoca o literal, ou seja, a redução mínima do sujeito na sua mais profunda singularidade. Em outros termos, a letra é isso que marca o sujeito em seu corpo e determina seu aspecto subjetivo. Ela não se confunde com o significante, pois está no real, enquanto o significante está no simbólico (Lacan, 1971).

É, portanto, na articulação entre o simbólico e o real que o método psicanalítico opera em busca da verdadeira singularidade do sujeito. É através da fala, com o recurso da associação livre, que uma análise segue seu curso e é pelo ato analítico que o analista conduz o processo a fim de fazer o real do gozo cessar de se inscrever. Isso indica uma virada na orientação da direção da cura na obra de Lacan. É desta linguagem opaca e não-toda que ao fim de sua análise o sujeito constrói seu artifício, seu saber-fazer que exclui o sentido. A conclusão de uma análise implica, assim, uma invenção sobre a letra, ou seja, um saber-fazer com esse ponto indizível e irrepresentável do gozo único. 
Essa lógica lacaniana pressupõe que o furo fundamental do sujeito - que é, na verdade, esse real sem lei e sem sentido - não pode ser preenchido. No entanto, ele pode ser contornado pela invenção. O termo invenção é aqui compreendido como um modo de lidar com o real. A invenção de que se trata está relacionada a um saber-fazer com o real. Compreendemos que é nesse sentido que o percurso analítico se aproxima do fazer artístico contemporâneo posto que o saber-fazer com o real é uma questão de se deixar tocar pelo real. Para além da técnica, na medida em que o artista de nosso tempo se afasta da mimese e faz de seu ato sua obra, ele toca algo que está para além do objeto; ele toca o indizível, o incompreensível. Assim, o artista surpreende na medida em que produz algo com um toque de real e isso só se dá quando ele mesmo é tocado por esse real.

Na arte contemporânea, o artista mostra que não há nada a ser colocado sobre o vazio central da Coisa (Brousse, 2009a, p. 31). O artista de hoje rompe com o semblante e evoca o real. Diríamos que esse é o novo lugar dado à sublimação, ou seja, o artista faz uma operação de redução do imaginário pela simbolização radical do significante sozinho, sem nenhuma significação, mostrando no campo da arte a marca assemântica do simbólico. Esta arte apresenta o traço singular da letra, ou seja, da redução significante até o ponto em que o estatuto do fora de sentido da linguagem emerge e caracteriza o real. A obra é criada sobre o esvaziamento de sentido e emersão da letra. É nesse sentido que a arte contemporânea e a psicanálise lacaniana ganham um ponto em comum.

\section{IV - Aspectos da invenção a partir da perspectiva lacaniana do real}

Se a invenção é a saída possível para lidar com o real, podemos supor que se não for pela análise, será pela atividade artística que o sujeito tratará seu gozo. Mas afirmar que essas são as duas formas de lidar com o gozo não significa dizer que elas são a mesma coisa, como veremos mais adiante.

No Seminário 23, Lacan (1975-1976) afirma que o simbólico só se sustenta pela função de furo no real, ou seja, a eficácia da língua depende de sua capacidade de contornar a impossibilidade de tudo dizer. $O$ trabalho analítico acontece sobre essa vacilação da linguagem. Isso é o que permite ao sujeito inventar uma solução para as consequências dos efeitos da letra em sua subjetividade e em seu modo de gozo.

Compreendemos que a invenção é uma forma de lidar com o real e ao invés de buscar um saber sobre a verdade do real, Lacan propõe um saber-fazer com ele, já que tal verdade é sempre um engodo. Assim, a maneira possível de lidar com o real sem lei é pela invenção de um artifício que contenha o estilo próprio do sujeito. Nesse sentido, aposta-se que ao final de análise ele se reencontrará com aquilo que lhe é mais singular com o qual seguirá sua vida. O sujeito inventa seu artifício com um elemento que já lhe pertence, ou seja, com seu modo de gozar.

Podemos dizer que na medida em que o termo invenção é empregado no contexto analítico, ele evoca a arte. Mas antes de relacioná-los é preciso lembrar que originalmente este 
termo tem relação com a Igreja como um atributo de Deus, o Criador, que cria o mundo a partir do nada. Na cultura, o ideal de criar ou inventar a partir do nada foi durante muito tempo um privilégio dado somente aos artistas. Entretanto, o Modernismo atacou esse ideal e a história da arte foi deixando para traz o imperativo da invenção de um objeto inédito ou da criação plástica sem igual. Com o nascimento da arte moderna, o termo criação muda seu paradigma e deixa de ser sinônimo de inovação. A partir desse momento, aquilo que o artista dá a ver não é mais a perfeição de uma representação. A arte de século XX fez obra de um objeto comum, fabricado ou mesmo desprezado. E a partir daí a arte se define como aquilo que faz enigma, que coloca uma questão, e não mais como uma perfeição técnica de representação da realidade. É preciso se perguntar, por exemplo, o que Wahrol quer dizer quando pinta caixas de sopa Campbell e as expõe num museu dando a elas o estatuto de obra de arte. Desde Manet a arte não pretende mais interpretar o mundo, mas convidar o espectador a mudar sua maneira de ver o mundo. Não se trata mais de oferecer ao olhar algo novo e sim de mudar a forma de olhar as coisas. $\mathrm{Na}$ modernidade, esses dois rios se afastam: dar a ver o novo, e fazer ver de uma nova maneira (Wajcman, 1998, p. 43).

Essa perspectiva ensina que, ao invés de convidar o espectador a contemplar a obra, a arte convida o olhar e o pensamento. As obras colocam questões, elas fazem enigma. Gérard Wajcman (1998) recorre ao "Quadrado negro sobre fundo branco" de Malevitch para explicar a lógica moderna introduzida no campo da arte. Esta obra minimalista não apresenta nada que possa ser visto. Ela não representa nada, nem mesmo um quadrado já que do ponto de vista geométrico o quadrado pintado é desproporcional. Ao enigma sobre o que resta de arte nesse quadro vazio de símbolo e de representação, Malevitch indica que resta a essência da pintura, o quadro puro e simples, "a pintura reduzida ao pictural" (Wajcman, 1998, p. 54). Tomar a obra como um oráculo: eis aí o que se deve fazer diante uma obra de arte contemporânea. Assim, a criação no contexto da arte convida à reflexão, mais do que à contemplação. É nesse sentido que a dimensão do conceito de invenção ganha um novo estatuto e é nesse caminho que podemos relacioná-lo com a teoria lacaniana do real. Esse "Quadrado negro" não é uma obra sem nada, ele é um quadro com o nada. É a própria falta que se pinta nele (Wajcman, 1998, p. 109). Sem símbolo e sem imagem, este quadro encarna a falta real. E é fazendo este uso do real, ou seja, furando o sentido, que o artista pode verdadeiramente inventar uma obra.

\section{V - Do sinthoma e da obra contemporânea, duas formas de inventar e de fazer emergir o sujeito}

O que se espera de uma análise é uma solução para o imperativo do real. Tal solução é também buscada pelo artista. Contudo, este não atravessa o percurso de depuração do sintoma, como faz o analista. Da mesma forma não podemos dizer que ao fim de uma análise o sujeito se torne um artista mesmo que ele escreva, em seu percurso, uma história, sua própria história. Sua escrita não é uma obra literária, embora, assim como o poeta, ele trabalhe com o furo do sentido. 
Ambos lidam com o non-sens, mas, se de um lado o artista se esforça para eliminar o sentido - a arte contemporânea não visa ser interpretada, ela é o que é -, de outro, o analista consente com a impossibilidade de a tudo dar sentido.

\section{A invenção analítica}

Lacan constrói uma teoria original em seu Seminário 23, onde introduz a ideia de savoirmieux-vivre com as marcas da letra que se apresentam enquanto sintoma. Na lógica inovadora proposta por Lacan, o sintoma que o sujeito apresenta no começo de sua análise como um problema torna-se, com a experiência analítica, o sinthoma como solução para o sujeito (Laia, 2008). O sinthoma é, por assim dizer, a reinvenção do sintoma.

Segundo a teoria lacaniana, o sintoma é uma tentativa mal sucedida de gerir o real. As consequências disso na subjetividade do indivíduo nós chamamos de gozo. É por ser uma tentativa fracassada que é preciso fazer uma borda e uma contenção nesse real a fim de tornar possível outro uso do gozo, um uso que não seja pelas vias do sofrimento.

Em sua conferência intitulada "A terceira", Lacan (1974) afirma que o sintoma é justamente isso que se coloca como um obstáculo: cada um tem um sintoma no percurso de sua vida. Jacques-Alain Miller (1998) indica que é preciso lapidar essa pedra que se encontra no meio do caminho. O processo analítico seria, assim, o trabalho de lapidação que implica na extração de um saber sobre o sintoma, um saber que Lacan define em seu Seminário 23 como savoir-y-faire. É preciso saber fazer algo com o real da satisfação libidinal. O sujeito não fica isento de seu gozo, por isso é preciso fazer dele ou com ele um uso menos nefasto. Saber-fazer com o sintoma não tem nada a ver com um saber teórico ou de uma verdade. Trata-se de um saber se virar na medida em que o sujeito lança mão do sintoma como uma ferramenta. Esta indicação está longe de vislumbrar um domínio do sintoma, ela propõe tomá-lo como parceiro. Assim, o sintoma que tinha o estatuto de problema no início do percurso perde seu caráter patológico ao final dele.

Jacques-Alain Miller (2004-2005) diz que seguimos uma análise tentando decifrar o real até o momento em que tropeçamos naquilo que não podemos mais compreender, naquilo a que não se pode mais dar sentido. É aí que encontramos o traço do sinthoma. Ao final de uma análise o estatuto do sintoma não é o mesmo do começo. A princípio o que está em jogo é o que não vai bem, o que faz sofrer por ser um obstáculo. Mas durante o processo analítico isso se converte na identificação ao modo de gozar. O desafio do fim de análise é tomar o sintoma como uma parte do real com a qual o sujeito pode viver. De uma forma ou de outra, nos diz Sérgio Laia (2008), é isso que ele faz durante sua vida com seu sintoma. Contudo, a experiência analítica torna possível a depuração do sintoma em direção ao savoir-y-faire. Ao final de sua análise o sujeito se reencontra com a singularidade de sua existência. Isso quer dizer que numa análise a pulsão perde sua força destrutiva. Entramos na experiência analítica divididos e não saímos dela curados de nossa pulsão. Mas saber manejar o que dela resta no sintoma é dignificá-lo como invenção, isto é, como a criação de um artifício único, forjado da singularidade do sujeito. Compreendemos, portanto, que é 
da insuficiência e dos furos do real da letra que o sujeito pode inventar seu sinthoma de fim de análise.

\section{A invenção na arte contemporânea}

Como vimos, o termo invenção é determinado no contexto artístico atual pela liberação das formalidades da tradição da arte. Isso abre possibilidade para uma nova definição de obra na qual é preciso passar da experiência do sentido a partir da contemplação, para a experiência do pensamento a partir do questionamento daquilo que está mais além do visual. Desta forma, o artista não cria nada novo, belo ou sublime, ele coloca uma questão para o espectador e uma pergunta se torna fundamental para que um objeto tenha o estatuto de arte: por que isso pode ser considerado uma obra?

O desafio da arte contemporânea é construir representações que critiquem a tradição representacional e mimética. Esta arte ultrapassa dispositivos tradicionais e mistura gêneros (como o teatro, a dança, o vídeo, as artes plásticas etc.), discursos e formações. Ela se opõe à consistência e se coloca do lado do não-todo (Brousse, 2009b, p. 203). Para além da técnica, em sua obra o artista toca o incompreensível. A arte não supõe mais um saber aprendido ou universalizado. $O$ artista surpreende quando trabalha com o singular de seu ato, tocando o real. Desta forma, compreendemos como obra de arte aquilo que traz o real para a ordem do dia, um real dessimbolizado situado para além da imagem e que desfaz o efeito de interpretação metafórica. $O$ objeto de arte não tem mais relação com o sentido e rompe com a realidade. Ele é real (Brousse, 2009b). Essa proposição da arte contemporânea coloca o artista no lugar de sujeito dividido, retirando-o da posição de mestre da criação. E é na condição de sujeitos divididos que os artistas podem fabricar um objeto verdadeiramente novo. Dito de outra forma, tocados pelo real sem lei, os artistas dos dias de hoje inventam, com suas obras, um saber-fazer aí onde qualquer possibilidade de representação ou de simbolização falha.

\section{VI - Conclusão: savoir-y-faire, a invenção com o real}

Tanto o artista quanto o analista criam subjetivamente formas de lidar com o real. Ambos criam um artifício ali onde esbarram no real. Supomos, portanto, que existam duas vias possíveis para tratar o gozo: seja pela arte ou pela psicanálise. Contudo, o artista não visa o "efeito-sujeito" embora utilize sua divisão subjetiva como material ou método (Brousse, 2009a, p. 35). Por outro lado, a experiência analítica implica na depuração do sintoma que leva à queda da crença do saber sobre a essência de uma verdade. É com a análise que o sujeito se dá conta de que não é possível dizer toda a verdade porque as palavras serão sempre insuficientes. É impossível estabelecer uma verdade posto que há sempre uma parte de real que exclui o sentido. Assim, Lacan indica que a verdade só pode ser encontrada como engodo. Ela é um semblante. O verdadeiro engana e o real se encontra no engodo da verdade. $O$ fim de análise é marcado pela queda da crença de um saber sobre uma verdade. $\mathrm{O}$ analisante, então, deve inventar algo com esta verdade equivocada. Por 
outro lado, no caso da arte, o artista crê em sua obra. Ele crê num saber, ele crê em seu sintoma (Laurent, 1998). Ele acredita na existência de uma verdade última por traz de seu sintoma com a qual realiza seu trabalho. Talvez esteja aí neste ponto a verdadeira diferença entre a invenção artística e a invenção analítica.

\section{Nota:}

${ }^{1}$ Texto extraído do projeto de pesquisa de doutorado da autora que está sendo realizada no departamento de Psicanálise da Université Paris VIII Vincennes Saint-Denis, com orientação do Prof. Dr. Gérard Wajcman.

\section{Referências bibliográficas}

Archer, M. (2001). Arte contemporânea - Uma história concisa. São Paulo: Martins Fontes.

Brousse, M.-H. (2009a). O saber dos artistas. In Lima, M. M. de L. \& Coutinho Jorge, M. A. (Orgs.) Saber fazer com o real: diálogos entre psicanálise e arte (pp. 31-37). Rio de Janeiro: Cia. de Freud.

Brousse, M.-H. (2009b, jun.). L'objet d'art à l'époque de la fin du beau. La cause freudienne, 71, 201-205. Paris: Navarin.

Freud, S. (1996). Projeto para uma psicologia científica. Edição standard brasileira das obras psicológicas completas de Sigmund Freud (Vol. 1, pp. 335-454). Rio de Janeiro: Imago (Trabalho original publicado em 1950[1895]).

Freud, S. (1985). Le créateur littéraire et la fantaisie. Féron, B. (Trad.) L'inquiétante étrangeté et autres essais (pp. 11-19). Paris: Gallimard (Trabalho original publicado em 1908[1907]).

Freud, S. (1987). Un souvenir d'enfance de Léonard de Vinci. In Altounian, J., Bourguignon, A., Cotet, P. \& Rauzy, A. (Trads.). Paris: Gallimard (Trabalho original publicado em 1910).

Freud, S. (1968). Pulsion et destin des pulsions, métapsychologie. In Laplanche, J. \& Pontalis, J.-B (Trads.). Paris: Gallimard (Trabalho original publicado em 1915).

Guerra, A. M. C. (2009). Sutilezas do tratamento do real no final do ensino lacaniano: a letra, o savoir-y-faire e l'âme à tiers. In Lima, M. M. de L. \& Coutinho Jorge, M. A. (Orgs.) Saber fazer com o real: diálogos entre psicanálise e arte (pp. 131-143). Rio de Janeiro: Cia. de Freud.

Lacan, J. (1996). Fonction et champ de la parole et du langage en psychanalyse. Écrits (pp. 237322). Paris: Seuil (Trabalho original publicado em 1953).

Lacan, J. (1996). L'instance de la lettre dans l'inconscient. Écrits (pp. 493-528). Paris: Seuil (Trabalho original publicado em 1957).

Lacan, J. (1986). Le Séminaire, livre VII: l'éthique de la psychanalyse. Paris: Seuil (Trabalho original publicado em 1959-1960).

Lacan, J. (1973). Le Séminaire, livre XI: les quatre concepts fondamentaux de la psychanalyse. Paris: Seuil (Trabalho original publicado em 1964-1965). 
Lacan, J. (2001). Lituraterre. Autres écrits (pp. 11-20). Paris: Seuil (Trabalho original publicado em 1971).

Lacan, J. (1975). La troisième - Intervention au Congrès de Rome. Lettres de l'Ecole freudienne, 16, 177-203. Paris: EFP (Trabalho original publicado em 1974).

Lacan, J. (2005). Le séminaire, livre XXIII: le sinthome. Paris: Seuil (Trabalho original publicado em 1975-1976).

Laurent, E. (1998, out.). Les paradoxes de l'identification. Cahier - Association de la Cause Freudienne Val-de-Loire et Bretagne, 11, 87-99. Rennes: ACF/VLB.

Laia, S. (2008, mai.-out.). O sintoma como problema e solução. Revista aSEPHallus, 6(3), 64-72. Recuperado de http://www.isepol.com/asephallus/numero 06/artigo 03.htm.

Miller, J.-A. (1998). O osso de uma análise. Salvador: EBP-Bahia.

Miller, J.-A. (2004-2005). Pièces détachées. La Cause Freudienne, (60) 153-172, (61) 131-153, (62) 75-83 \& (63) 119-145. Paris: Seuil.

Miller, J.-A. (2009). Perspectivas do Seminário 23 de Lacan, o sinthoma. Rio de Janeiro: Zahar.

Recalcatti, M. (2005). As três estéticas de Lacan. Opção Lacaniana - Revista Brasileira Internacional de Psicanálise, (42) 94-108. SP: Eólia.

Regnault, F. (1995). El arte según Lacan y otras conferencias. Barcelona: Eolia.

Rivera, T. (2002). Arte e psicanálise. Rio de Janeiro: Jorge Zahar.

Rivera, T. (2009). O retorno do sujeito e a crítica na arte contemporânea. Recuperado de www.seminariosmv.org.br/2009/textos/04 tania.pdf.

Rivera, T. (2010). Estética e descentramento do sujeito. CULT, (125) 50-53. São Paulo: Bregantini (Trabalho original publicado em jun. 2008).

Stangos, N. (1991). Conceitos da arte moderna. Rio de Janeiro: Jorge Zahar.

Wajcman, G. (1998). L'objet du siècle. Paris: Verdier.

Wajcman, G. (2000). L'art, la psychanalyse, le siècle. L'écrit, l'image, 27-53. Paris: Champs Flammarion.

Citacão/Citation: Mello, L. (mai. a out. 2014). Um estudo sobre o real e sua relação com a invenção artística e psicanalítica. Revista aSEPHallus de Orientação Lacaniana, 9(18), 50-60. Disponível em www.isepol.com/asephallus. doi: 10.17852/1809-709x.2019v9n18p50-60.

Editor do artigo: Tania Coelho dos Santos.

Recebido/Received: 24/11/2013 / 11/24/2013.

Aceito/Accepted: 18/12/2013 / 12/18/2013.

Copyright: (c) 2013 Associação Núcleo Sephora de Pesquisa sobre o moderno e o contemporâneo. Este é um artigo de livre acesso, que permite uso irrestrito, distribuição e reprodução em qualquer meio, desde que o autor e a fonte sejam citados/This is an open-access article, which permites unrestricted use, distribution, and reproduction in any medium, provided the author and source are credited. 